\title{
Ascertaining of temporomandibular disorders (TMD) with clinical and instrumental methods in the group of young adults
}

\author{
Anna Sójka', Juliusz Huber², Elżbieta Kaczmarek³, Wiesław Hędzelek' \\ ${ }^{1}$ Department of Prosthodontics, Poznan University of Medical Sciences, Poland \\ 2 Department of Pathophysiology of Locomotor Organs, Poznan University of Medical Sciences, Poland \\ ${ }^{3}$ Department of Bioinformatics and Computational Biology, Poznan University of Medical Sciences, Poland
}

ABSTRACT

Introduction. During the diagnostic process, the clinical examination of the masticatory system combined with jaw movement measurements can indicate the presence of temporomandibular disorders (TMD) symptoms.

Aim. The aim of the present study was to determine the presence of clinical symptoms of TMD in a group of subjects aged 19-27 years and to analyze the measurable parameters obtained from examinations carried out using the Arcus $^{\circledR}$ digma.

Material and methods. Eighty four dentate subjects from 19 to 27 years were recruited from students. Objective signs were studied with Helkimo Anamnetic index ( $\mathrm{Ai}$ ) and the subjective symptoms were evaluated with Gsellmann's Occlusal Index (OI). Functional examination of the masticatory system was performed using Helkimo Clinical Dysfunction index (Di). Pain symptoms were determined in clinical examination using visual analogue scale. Software of Arcus ${ }^{\circledR}$ digma allowed the analysis of Bennett's angle and movement, the horizontal condylar inclination, retrusion, anterior guidance and Immediate Side Shift.

Results. Occasional pain occurred in 39\% of students and correlated with increase of OI index, subjects with higher Di displayed higher values of OI. Comparison of Bennett's angle values for the right and left TMJ showed the significant asymmetry, similarly like the values of Bennett's movement and retrusion between the left and right TMJ.

Conclusions. Bennett's angle, Bennett's movement and retrusion were significant parameters in instrumental evaluation of TMD symptoms. The questionnaire and clinical examination supplemented with axiographic recordings revealed the presence of TMD symptoms in students who were not fully aware of TMJ disorders.

Keywords: temporomandibular disorders, clinical examination, axiography, measurable parameters.

\section{Introduction}

During the diagnostic process, jaw movement measurements combined with clinical examination of the masticatory system and the subjective report of pain can indicate the presence or absence of temporomandibular disorders symptoms. Clinical examination is the gold standard for diagnosing temporomandibular disorders (TMD) and involves assessment of jaw movements, acoustic symptoms, tenderness in jaw muscles and temporomandibular joints [1]. Condylar move- ments are not only determined by the pathologies in articular eminence, the disc and the ligaments of the temporomandibular joint but also by the occlusal and neuromuscular factors [2]. Axiography is a major part of instrumental analyses in clinical dental practices to evaluate functional states of the stomatognathic system. Recently, individual recording of mandibular movements has been made possible using the electronic jaw recording system. Patients with TMD frequently exhibit changes in the mandibular movements. 
Electronic jaw recording systems (like Arcus ${ }^{\circledR}$ digma or Cadiax ${ }^{\circledR}$ systems) in patients with TMD display changes in patterns of jaw movements such as shortening or asymmetry in the condylar pathways. This is a noninvasive diagnostic method which allows the determination of the hinge axis as well as assessment of measurable parameters like Bennett's angle, the horizontal condylar inclination $(\mathrm{HCl})$, shift angle, retrusion, incisal inclination during protrusion and laterotrusion and Immediate Side Shift (ISS). These parameters can be recorded for diagnostic purposes [3-5]. Few articles are available on the analysis of measurable parameters obtained from Arcus ${ }^{\circledR}$ digma and on their importance in the diagnosis of TMD.

The aim of present study was to determine the first symptoms of TMD in a group of subjects aged from 19 to 27 years, confirmed by the chosen measurable parameters obtained from examinations carried out using the $\operatorname{Arcus}^{\circledR}$ digma.

\section{Material and methods}

Eighty four dentate subjects (66 women and 18 men) aged from 19 to 27 years (mean 23 years \pm 2 years) were recruited from university students to the study. They were recruited randomly and expressed a wish to check the functioning of the stomatognathic system. All they represented a similar body constitution and the anthropometric properties. Inclusion criteria were: good general health status without acute and chronic pain symptoms, full dentition, and stable occlusion, no prosthetic restorations either fixed or removable. Exclusion criteria were: former injury to the head and neck, dentofacial deformity or surgery of the temporomandibular joint (TMJ), TMJ trauma with chronic pain, concurrent systemic diseases, undergoing pharmacological therapy with drugs which might affect psycho-physical condition, orthodontic treatment. History was taken and an assessment form was filled. Those subjects whose treatment of TMD was expected before were excluded from the study.

\section{Clinical studies}

Pain sensation was evaluated by the Visual Analogy Scale (VAS) within the area of temporomandibular joint. Objective and subjective evaluation of signs was carried out. Objective signs were evaluated using the Helkimo Anamnetic Index (Ai) and the subjective symptoms with the Gsellmann's Occlusal Index (OI). Ai was scored based on the different symptoms of dysfunction in the masticatory system (subjective symptoms) reported by the individuals during history taking. Such index have three levels as follows: Ai-O made up of individuals free from dysfunction symptoms, Ai-I, made up of individuals with mild dysfunction symptoms, Ai-II, made up of individuals with severe dysfunction symptoms. Functional examination of the masticatory organ using the Helkimo Clinical Dysfunction Index of TMD (Di) was performed. Helkimo $\mathrm{Di}=0(\mathrm{Di}=0)$ indicates no clinical signs of TMD, Helkimo $D i=I(D i=l)$ mild signs, Helkimo $\mathrm{Di}=\| \mathrm{I}(\mathrm{Di}=\mathrm{II})$ moderate symptoms, Helkimo $\mathrm{Di}=\mathrm{III}(\mathrm{Di}=\mathrm{III})$ severe symptoms. In accordance with the presence and/or severity of clinical symptoms, individuals were assigned a score of 0,1 , or 5 points. The following symptoms could have been were observed: range of mandibular motion, TMJ function impairment, muscle tenderness during palpation, TMJ pain during palpation, pain during mandibular movement - only recorded when clearly identified. According to the score obtained, the subjects were classified in four groups: Di-0, 0 points - subjects clinically free from dysfunction symptoms, Di-I, 1 to 4 points - subjects with mild dysfunction symptoms, Di-II, 5 to 9 points subjects with moderate dysfunction symptoms, Di-III, 10 to 25 points - subjects with severe dysfunction symptoms. The $\mathrm{OI}$ is based on 10 questions evaluating the subjects' symptoms within the stomatognathic system. Positive responses were graded as symptoms: $1=$ light, $2=$ medium, 3 = severe. The sum of the graded answers divided by the number of positive answers constitutes the Occlusal Index $[3,6,7]$.

\section{Axiographic recordings}

Mandibular movements were recorded with an ultrasound based electronic Arcus ${ }^{\circledR}$ digma system (Arcus ${ }^{\circledR}$ digma, KaVo, Germany). During axiographic recording, the subject was seated in an upright position. First, the head frame with the receivers was attached. The maxillary position was determined with a bite plate, which had previously been individualized with hard silicone (EliteHD+Putty Zhermack). Next, a paraocclusal clutch was fixed with acrylic resin (Struktur 2 SC, VOCO) and was cemented with policarboxillic cement to the facial surfaces of the mandibular premolar and anterior teeth. Paraocclusal clutch did not interfere with the occlusion. The following tooth guided mandibular movements were recorded after initial instruction: maximum protrusive movement, maximum lateral movement to the right side, and maximum lateral movement to the left side. The measurements were processed with software allowing the calculation of the Bennett's angle, the horizontal condylar inclination, 
individual mandibular side shift, the so-called Bennett's movement, retrusion, incisal inclination during protrusion and laterotrusion the so-called anterior guidance middle, left, right and Immediate Side Shift automatically. The measurable parameters values were referred statistically to the reference provided by $\operatorname{Arcus}^{\circledR}$ digma and to the examination results.

Ethical considerations were in agreement with the Helsinki Declaration. Approval was also received from the Bioethical Committee of University of Medical Sciences. Each subject was informed about the aim of study and gave written consent for examinations and data publication.

\section{Statistical analysis}

The sensation of pain rated as VAS scores, Helkimo Ai, $\mathrm{Ol}$, elicited from history and obtained from examinations are presented in the tables as counts (in absolute numbers) and as frequency (prevalence) expressed in percentage. The correlation of pain index (VAS scores and OI) with the clinical indexes was assessed using the Spearman rank correlation coefficient. Quantitative parameters of mandibular movements are presented in tables of mean values, standard deviations and minimal and maximal results. After evaluation of variance homogeneity results of these parameters were compared between left and right side using nonparametric paired Wilcoxon test. The results were considered as statistically significant at $p<0.05$. Statistical analysis was performed using Statistica v. 9.0 (Stat Soft Inc).

\section{Results}

The VAS scores of 0 to 10 were applied to evaluate subjective and periodic pain and discomfort in the studied group of 84 subjects where 0 indicated no discomfort or pain. Such score was noted in 51 people (60.71\%). Twenty three $(27.38 \%)$ presented no subjective TMJ complaints $\mathrm{Ai}=0$, and 61 subjects $(72.62 \%)$ reported slight subjective complaints $\mathrm{Ai}=\mathrm{I}$. The difference between the subjects reporting

Table 1. Prevalence of TMDs according to anamnestic Helkimo index Ai and clinical Helkimo index Di

\begin{tabular}{cccccc}
\hline \multicolumn{3}{c}{ Anamnestic Helkimo index } & \multicolumn{3}{c}{ Clinical Helkimo index } \\
\hline $\mathrm{Ai}$ & Counts & $\%$ & $\mathrm{Di}$ & Counts & $\%$ \\
\hline 0 & 23 & 27.38 & 0 & 15 & 17.86 \\
\hline 1 & 61 & 72.62 & $\mathrm{I}$ & 49 & 58.33 \\
\hline 2 & 0 & 0 & II & 20 & 23.81 \\
\hline Total & 84 & 100 & Total & 84 & 100 \\
\hline
\end{tabular}

and not reporting subjective complaints was statistically significant $(p<0.01)$. In the studied group no severe complaints were reported $\mathrm{Ai}=$ II (Table 1$)$. In the studied group $\mathrm{Di}=$ I (58.33\%) was most common. $\mathrm{Di}=$ II was noted in significantly $(p<0.01)$ smaller number of people (23.81\%). The clinical index $\mathrm{Di}=0$ was present in $17.86 \%$, insignificantly different from $\mathrm{Di}=$ II (Table 1).

\section{Subjective Occlusal Index by Gsellmann}

In the studied group of 84 subjects, 14 (16.67\%) reported no subjective complaints of TMJ dysfunction according to Ol, 21 (25.00\%) - showed a single subjective symptom what indicated a mild form of TMJ dysfunction, 31 (36.90\%) - showed two symptoms indicating a medium dysfunction, and 18 (21.43\%) - three or more symptoms which proved a severe form of TMJ dysfunction (Table 2).

Pain and dysfunction severity was evaluated in the students using three scales: VAS, OI, Di. It showed statistically significant positive correlations. The correlation rate between VAS and OI was 0.56 ( $p<0.05$ ), however between Di and OI was higher and showed the value of 0.82 ( $p<0.05)$. An increase in VAS occurred with an increase in the Ol index and the subjects with higher Di displayed higher values of OI (Figure 1).

Comparison of measurable parameters of the right and left TMJ

Measurable parameters of the TMJ mandibular movements obtained instrumental studies are presented in

\section{Table 3.}

Comparing the values of the Bennett's angle for the right and left TMJ in the group of 84 subjects a statistically significant asymmetry at $p<0.0001$ was found (Figure 2) as well as statistically significant asymmetry at $p<0.0001$ for the values of Bennett movement between the left and right TMJ (Figure 3).

A statistically significant difference was found between retrusion parameters of the left $(L)$ and right (R) TMJ at $p<0.0001$ (Figure 4).

Table 2. Prevalence of TMDs according to Occlusal Index Ol by Gsellmann

\begin{tabular}{ccc}
\hline \multicolumn{3}{c}{ Occlusal Index (Gsellmann) } \\
\hline OI & Counts & $\%$ \\
\hline 0 & 14 & 16.67 \\
\hline 1 & 21 & 25.00 \\
\hline 2 & 31 & 36.90 \\
\hline 3 & 18 & 21.43 \\
\hline
\end{tabular}


No statistically significant difference was found between the horizontal condylar inclination of the right and left TMJ condylar pathway in the studied subjects. The difference between the values of immediate side shift for the left and right TMJ is statistically non-significant. The anterior guidance parameters for the right (R) and left (L) TMJ do not show statistically significant differences.

\section{Discussion}

Properly elicited history and a detailed clinical examination are the basis for any diagnosis of disorders affecting the human body. Temporomandibular joints, due to their complicated structure and function, sometimes require a wider range of diagnostic methods including those which enable recording and visualizing individual mandibular movements. Certainly instrumental methods can supply much information; however this may give rise to some problems such as a noticeable changeability in the movement parameters of the masticatory system present both between patients and between subsequent measurements of the same patient. The data analysis poses problems, too. Determining the border movements depends on TMJ anatomy, occlusal plane, and physiological lim-

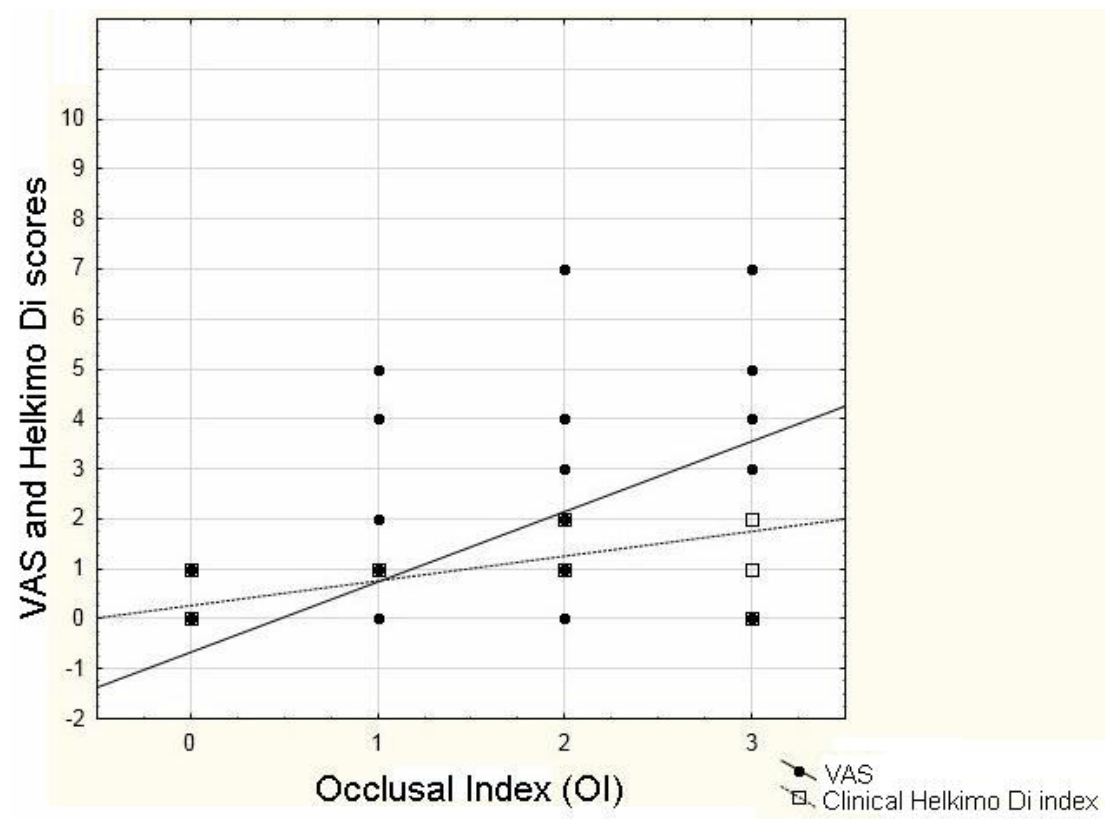

Figure 1. Correlation of 0 I and VAS $(r=0.56, p<0.05)$ and clinical Helkimo Di index $(r=0.82$, $p<0.05)$

Table 3. Quantitative parameters of mandibular movements measured in a group of 84 subjects using Arcus $^{\circledR}$ digma

\begin{tabular}{lcccc}
\hline \multicolumn{1}{c}{ Measurable parameters } & Mean & $\begin{array}{c}\text { Standard } \\
\text { Deviation }\end{array}$ & Minimum & Maximum \\
\hline Horizontal Condylar Inclination right TMJ $\left(^{\circ}\right)$ & 34.57 & 12.35 & 0.00 & 63.30 \\
\hline Horizontal Condylar Inclination left TMJ $\left(^{\circ}\right)$ & 36.47 & 11.68 & 0.00 & 63.90 \\
\hline Bennett angle right TMJ $\left(^{\circ}\right)$ & 8.09 & 5.59 & 4.00 & 30.00 \\
\hline Bennett angle left TMJ $\left(^{\circ}\right)$ & 12.28 & 7.19 & 4.00 & 30.00 \\
\hline Bennett movement right TMJ $\left({ }^{\circ}\right)$ & -8.62 & 14.81 & -20.00 & 20.00 \\
\hline Bennett movement left TMJ $\left(^{\circ}\right)$ & 4.08 & 15.92 & -20.00 & 20.00 \\
\hline Retrusion right TMJ $(\mathrm{mm})$ & 0.93 & 0.83 & 0.00 & 3.50 \\
\hline Retrusion left TMJ $(\mathrm{mm})$ & 0.46 & 0.78 & 0.00 & 4.20 \\
\hline Immediate Side Shift right TMJ $(\mathrm{mm})$ & 0.01 & 0.04 & 0.00 & 0.30 \\
\hline Immediate Side Shift left TMJ $(\mathrm{mm})$ & 0.01 & 0.04 & 0.00 & 0.30 \\
\hline Anterior guidance middle $\left({ }^{\circ}\right)$ & 40.16 & 18.19 & 0.00 & 66.90 \\
\hline Anterior guidance left $\left({ }^{\circ}\right)$ & 41.69 & 16.96 & -7.50 & 81.30 \\
\hline Anterior guidance right $\left({ }^{\circ}\right)$ & 43.20 & 15.84 & -5.00 & 69.60 \\
\hline
\end{tabular}




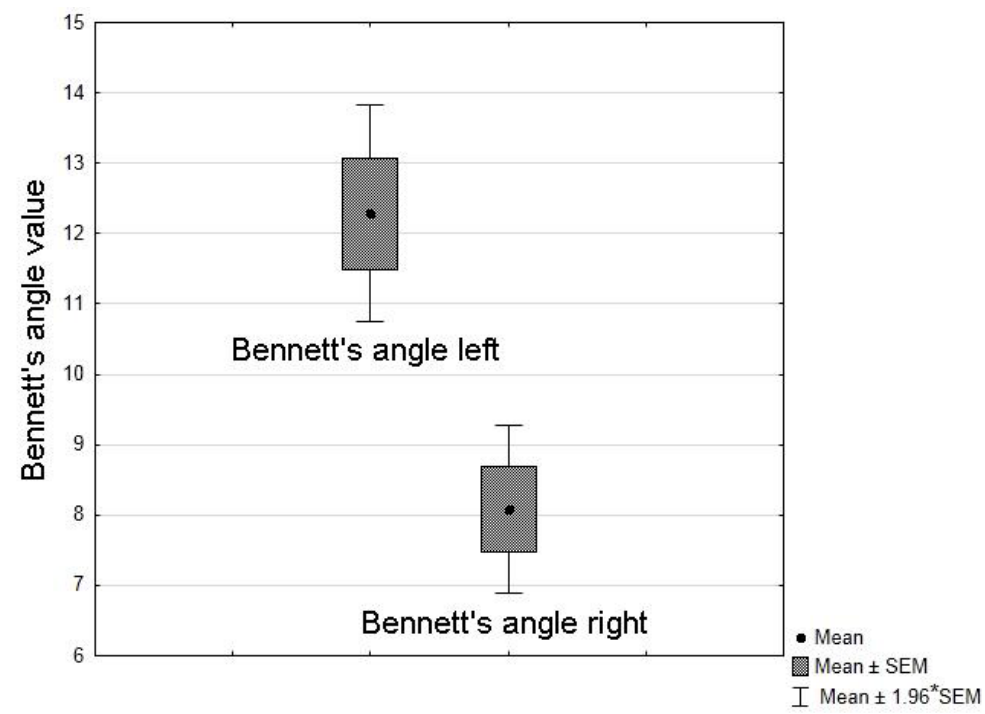

Figure 2. Bennett's angle in left and right TMJ $(p<0.0001)$

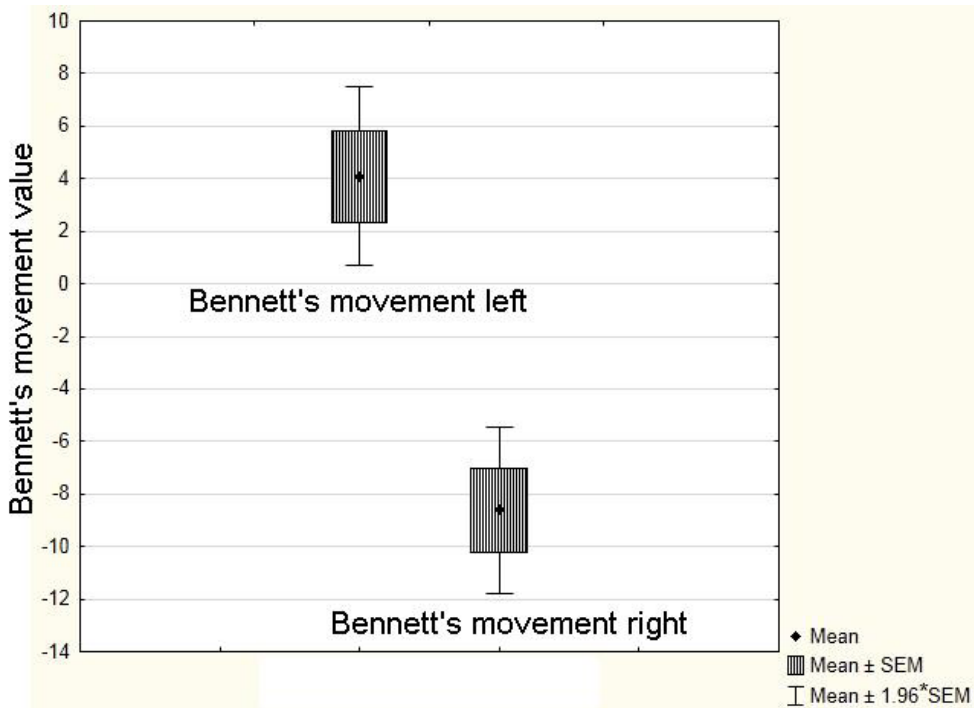

Figure 3. Bennett's movement in left and right TMJ $(p<0.0001)$

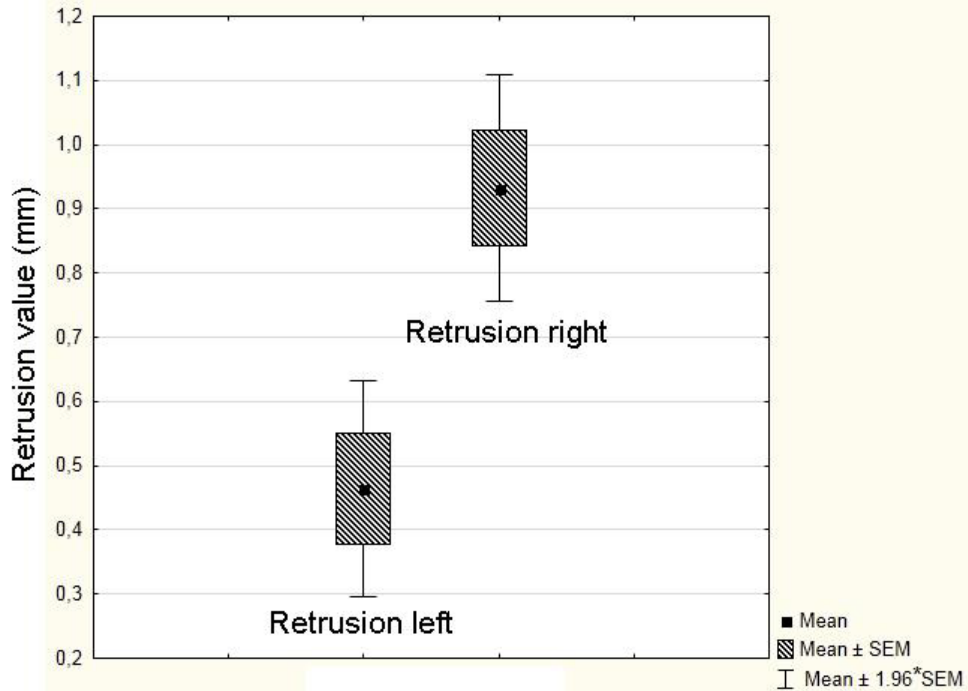

Figure 4. Retrusion of left and right TMJ $(p<0.0001)$ 
its related to the ligaments system. The application of a paraocclusal tray in instrumental diagnostics enabled comparative studies of maximal intercuspidation and retrusive contact position.

Since we analyzed a group of students aged 19-27 years currently studying at medical university and other higher education schools, an initial problem appeared to be the choice of a group of fully healthy individuals. Therefore, the studied group of 84 subjects was analyzed without constructing a group of controls. Following history taking and physical examination, the groups of students with clinical symptoms of TMD were determined. However, following instrumental examination all results in various groups with particular dysfunctions were analyzed. In order to evaluate masticatory system function subjective indices were applied (Helkimo Ai and Gsellmann's Occlusal Index).

Clinical signs evaluation was done by Helkimo Di index. In the 1970's the author of these indices M. Helkimo basing on his observations noted major problems while evaluating various groups of patients $[6,7]$. To facilitate comparison of these groups it was necessary to convert the results to numbers what would make the evaluation of symptoms frequency and severity easier. Since such an evaluation system was formulated by Helkimo, it has been commonly used for the evaluation of the masticatory system dysfunction. The subjective Gsellmann's Occlusal Index (OI) shows higher sensitivity as it requires answering 10 questions and may make an additional diagnostic element [3].

During clinical examination face asymmetry should be noted, which may result from previous occlusal or skeletal disorders. Muscular hypertrophy may also be observed due to teeth clenching or grinding or to TMJ and/or muscle inflammation oedema [8]. Asymmetry may also occur in patients with the history of facial nerve inflammation. The studies of Inui et al. revealed face asymmetry to be related to mandibular asymmetry; it is a common complaint of people with TMJ dysfunction [9]. The mandible may shift towards the affected side to avoid biting obstacles arising from condyle dislocation in the mandibular fossa.

It is believed that the evaluation of the masticatory system movement cannot be done using mechanical devices alone, but should also be accompanied by detailed clinical and imaging examinations. It should be remembered that the use of mechanical devices for evaluation is a functional analysis where the results repeatability are affected by many factors such as the condition of the neuro-muscular system, time of the day, psycho-physical state of a patient [10]. Baqaien et al. showed that horizontal condylar inclination is steeper with every millimeter of a protrusive movement as well as with age [11]. Female population has a tendency towards steeper values of $\mathrm{HCl}$. However, in the study by Johnson and Winstanley, only $6-8 \%$ of the subjects showed the same $\mathrm{HCl}$ values [12]. In our study the average value of $\mathrm{HCl}$ for the right TMJ was $34.57^{\circ}$, for the left one $36.47^{\circ}$ (Table 3). A high value of standard deviation (12.35 - right and 11.68 - left TMJ) suggests marked individual fluctuations of this parameter. However, no statistically significant difference was established between $\mathrm{HCl}$ of the right and left TMJ. Comparing the values of the Bennett's angle of the right and left TMJ in the group of 84 people a statistically significant asymmetry was found at $p<0.0001$ (Figure 2). Average values of the Bennett movement parameter in the studied group for the right TMJ showed lateroretrusion of $-8.62^{\circ}$, for the left TMJ lateroretrusion was $4.08^{\circ}$ and standard deviation was 15.92 on average and displayed statistically significant asymmetry at $p<0.0001$ between the right and left TMJ (Table 3, Figure 3). In the studied group ISS for the right and left TMJ was $0.01 \mathrm{~mm}$ and the difference between the right and left TMJ was not statistically significant. In our studies the anterior guidance was $40.16^{\circ}$ and standard deviation was 18.19 and the difference was not statistically significant (Table 3 ). The statistical analysis of numeric values of measurable parameters in the group of 30 students studied by us before, showed a statistically significant difference for the Bennett movement parameter on the right and left side as well as for the retrusion parameter of the right and left side which could result from the left and right side asymmetry and from a TMJ disfunction. Tsuruta et al. showed greater shift from the maximum cuspidation to the reference position (central relation) in patients with condylar structural changes what may prove it is related to TMJ lesions [13]. An impact of retrusive movements on TMJ is unclear as in normal conditions the most retrusive mandibular position should be symmetrical on both sides. The temporomandibular joint may become compressed due to a retrusive movement of a working condyle, especially during parafunctions [14]. Results of instrumental recordings supplementing the results of clinical examination make possible to correctly diagnose the patient, ascertain the severity of TMD, give the basis for undertaking the implementation of directional prosthetic treatment. 


\section{Conclusions}

While diagnosing TMDs it is recommended to apply both: the indices of subjective and clinical examinations. The questionnaire and the clinical examination revealed the presence symptoms of TMD in the majority of healthy students and they were not aware of the presence of TMJ disorders.

Comparing the results of measurable parameters in the group of 84 subjects, the statistically significant asymmetry was found between the right and left TMJ concerning the Bennett's angle, Bennett's movement and retrusion. This may prove the significance of these parameters in TMD diagnostics and may be useful in planning the future treatment. Examination by the Arcus ${ }^{\circledR}$ digma device can show both the symmetry as well as the asymmetry in TMJ function.

The analysis of measurable parameters and function charts obtained with the Arcus ${ }^{\circledR}$ digma device, together with the clinical findings, enables immediate evaluation of TMJ condition what makes it valuable in the diagnostics, prognosis and management of TMDs. Further studies are required concerning measurable parameters obtained with instrumental techniques and their application in TMD diagnostics.

\section{Acknowledgements}

\section{Conflict of interest statement}

The authors declare that there is no conflict of interest in the authorship or publication of contribution.

\section{Funding sources}

There are no sources of funding to declare.

\section{References}

1. Masumi S, Kim YJ, Clark GT. The value of maximum motion measurements for distinguishing between common temporomandibular disorder subgroups. Oral Surg Oral Med Oral Pathol Oral Radiol Endod. 2002;93(5):552-559.

2. Okeson JP. Management of Temporomandibular Disorders and Occlusion. $4^{\text {th }}$ ed. St Louis: Mosby; 1998.

3. Gsellmann B, Schmid-Schwap M, Piehslinger E, Slavicek R. Lengths of condylar pathwaysmeasured with computerized axiography (Cadiax ${ }^{\circledR}$ ) and occlusal index in patients and volunteers. J Oral Rehabil. 1998;25:146-152.

4. Seedorf $H$, Seetzen F, Schulz A, Sadat-Khonsari MR, Kirsch I, Jude HD. Impact of posterior occlusal support on the condylar position. J Oral Rehabil. 2004;31:759763.

5. Stiesch-Scholz M, Demling A, Rosbach A. Reproducibility of jaw movements in patients with craniomandibular disorders. J Oral Rehabil. 2006;33:807-812.

6. Helkimo M. Studies on function and dysfunction of the masticatory system. II. Index foranamnestic and clinical dysfunction and ecclesial state. Swed Dent J. 1974;67:101-121.

7. Helkimo M. Studies on function and dysfunction of the masticatory system. III. Analyses of anamnestic and clinical recording of dysfunction with the aid of indices. Swed Dent J. 1974;67:165-182.

8. Ash MM, Nelson SJ. Wheeler's Dental Anatomy, Physiology and Occlusion. $8^{\text {th }}$ ed. St Louis: Saunders; 2003.

9. Inui M, Fushima K, Sato S. Facial asymmetry in temporomandibular joint disorders. J Oral Rehabil. 1999;26:402406.

10. Celar AG, Tamaki K. Accuracy of recording horizontal condylar inclination and Bennett angle with the Cadiax compact. J Oral Rehabil. 2002;29:1076-1081.

11. Baqaien MA, Al-Salti FM, Muessig D. Changes in condylar path inclination during maximum protrusion between the ages of 6 and 12 years. J Oral Rehabil. 2007;34:27-33.

12. Johnson A., Winstanley RB. Recording sagittal condylar angles using a mandibular facebow. J Oral Rehabil. 1997;24:904-908.

13. Tsuruta A, Hamada K, Hanada K, Koyama Jl, Hayashi T, Hosogai A et al. Comparison of condylar positions at intercuspal and reference positions in patients with condylar bone change. J Oral Rehabil. 2004;31:640-646.

14. Yang $Y$, Yatabe M, Ai M, Soneda K. The relation of canine guidance with laterotrusive movements at the incisal point and the working side condyle. J Oral Rehabil. 2000;27:911-917.

Acceptance for editing: 2015-02-10 Acceptance for publication: 2015-03-30

Correspondence address: Juliusz Huber Department of Pathophysiology of Locomotor Organs Poznan University of Medical Sciences Wiktor Dega Clinical Orthopaedic and Rehabilitation Hospital

28 Czerwca 1956 135/147 Str. 61-545, Poznań, Poland phone: +48618310230

fax: +48618310230 e-mail: zpnr@wp.pl 